\title{
The deterioration of basin and sediment overlapping in the infrastructure of the irrigation districts in Mexico
}

\author{
R. Lomeli ${ }^{1} \&$ N. Alvarez ${ }^{2}$ \\ ${ }^{1}$ Instituto Mexicano de Tecnología del Agua, México \\ ${ }^{2}$ Comisión Nacional del Agua, México
}

\begin{abstract}
The surface dedicated to agriculture in Mexico is of approximately 21 million hectares, of which 6.4 million count as irrigation infrastructure, and 3.5 million (54\%) correspond to 86 great areas called Irrigation Districts. The irrigated farming generates more than half of the national agricultural production. One of the main problems of the infrastructure maintenance is the accumulation of sediments in the distribution and drainage networks, caused fundamentally by insufficient actions of soils and water conservation in the basins of the irrigation dams. The present work analyzes the impact of the catchment basins degradation in the accumulation of sediments in the Irrigation Districts.

Keywords: sediment removal, irrigation districts maintenance, catchment basins, soil and water conservation works.
\end{abstract}

\section{Introduction}

In Mexico, the area dedicated to agricultural activity varies between 21 and 24 million hectares annually. The surface with infrastructure for irrigation is 6.4 million hectares, México ranks sixth place in the world, in terms of irrigation areas made of 86 Irrigation Districts with 3.5 million hectares and 39482 irrigation units of small irrigation with 2.9 million hectares [1-3].

In addition there are called Temporal Tecnificado districts that directly depend on the rainfall, with no irrigation infrastructure, but using different techniques and works to reduce the damage caused by the occurrence of heavy and prolonged rains or drought-, to improve the rain and moisture gathering in farming lands. 
The agricultural production of the Irrigation Districts contributes directly in the development of the country because it represents one third of the national food production, and involves over half a million of irrigation users. These products represent about $60 \%$ of the value of the domestic production.

The infrastructure of Irrigation Districts, are made up as follows [4]:

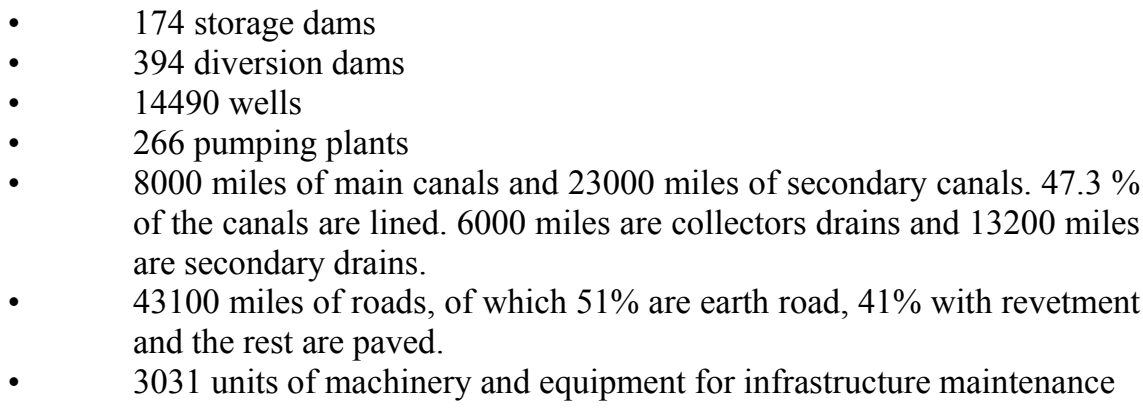

The following is a summary table of the classification of canals and drains, according to their main characteristics which are the bottom and the depth of water, as shown in figure 1.

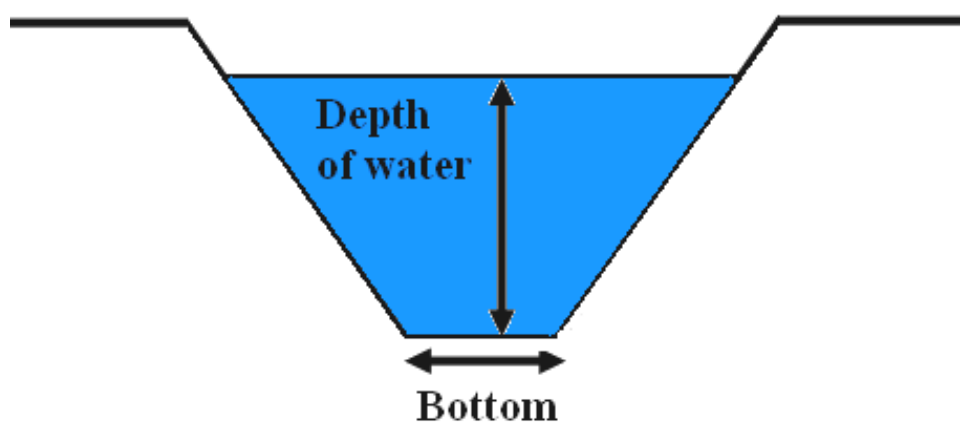

Figure 1: Cross section of canals and drains.

The infrastructure maintenance (conservation in Mexico) is an action to be performed periodically and permanently in order to preserve its state, under conditions closer to the original project.

To maintain in optimal conditions the infrastructure is essential to provide a good irrigation service, that is, to deliver water to crops timely and sufficient, which will get an optimum crop production.

The development of surface irrigation in Mexico is limited, and currently, there are few sources of water economically available, therefore, to maintain or improve the productivity of the Irrigation District is priority for optimal maintenance of infrastructure

The maintenance of the infrastructure is basic to improve the operation of the irrigation districts and to fulfill with the irrigation schedule. In Mexico to make a quick and economical field works, we use manpower, heavy weight machinery as long reach hydraulic excavator (Figure 2) and equipment as backhoe loaders. 


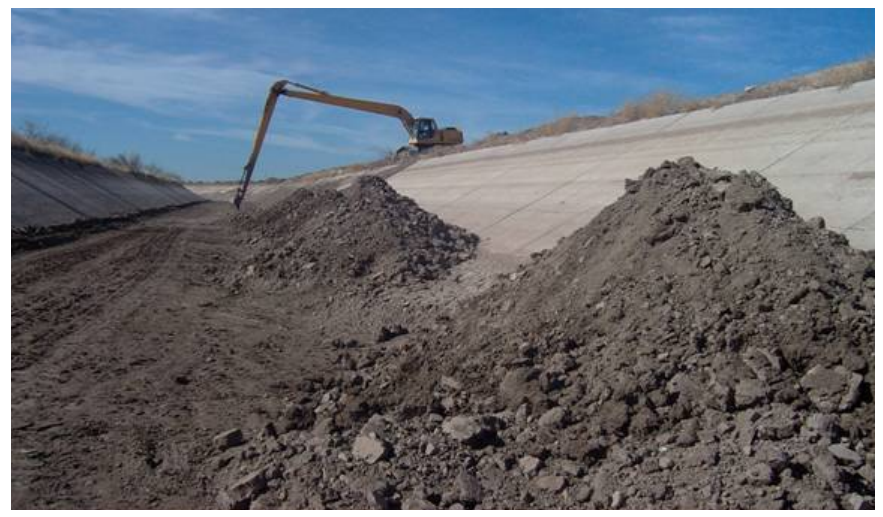

Figure 2: $\quad$ Long reach excavator removing sediments in an irrigation canal.

\section{Problematic}

The investment in infrastructure for irrigation is high, water to one hectare of land (dam construction, infrastructure, etc.) has a cost of over $5000 €$, the infrastructure rehabilitation requires approximately $1000 €$, while the maintenance, has a cost of about $18 €$, making it extremely profitable to perform the work of preserving the infrastructure of the irrigation districts to obtain the sustainable water use matter.

The main maintenance concepts are:

- Sediments removal in canals and drains.

- Tracking, forming and coating roads replacement.

- Repair of structures and mechanisms.

- Weed Control (aquatic and terrestrial).

- Canals slabs replacement.

- Dams, wells and pumping plant preventive maintenance

It should be noted that annually the irrigation Districts removes about 5.2 million cubic yards of sediments in distribution networks and more than 7.8 million in the drainage network that means more than 13 million cubic meters per year total.

In the following data from Organismo de Cuenca (Basins Agencies) are showed.

The main causes of sediment accumulation are:

- Uncontrolled water from natural channels into canals and drainage networks.

- Irrigation water with suspended solids.

- Inadequate protection of the canal slopes with grassland.

- Tail water. 


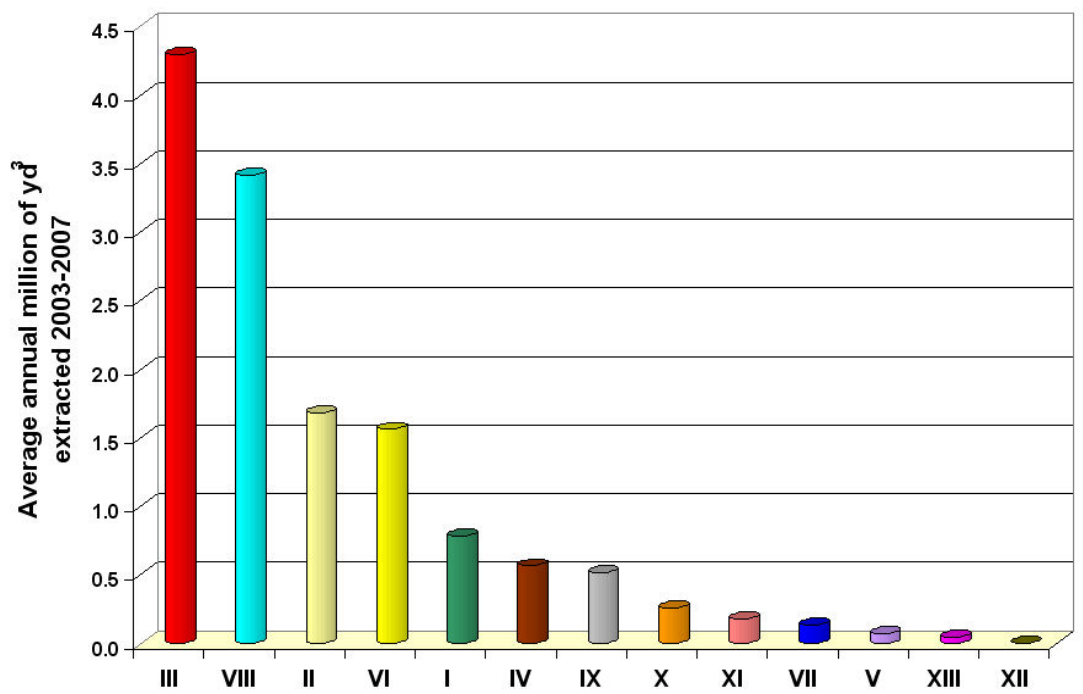

Figure 3: Average annual million of $\mathrm{yd}^{3}$ extracted 2003-2007 distributed by Basin Agency.

Most of the Irrigation Districts source is storage dams however there is not enough soil and water conservation works in their basins, which have caused soil erosion in the highlands. Water particles of such soil move down and deposits in the storage reservoirs, reducing the dams usefulness and later producing the accumulation of sediments in the distribution network. These sediments also facilitate the development of weeds.

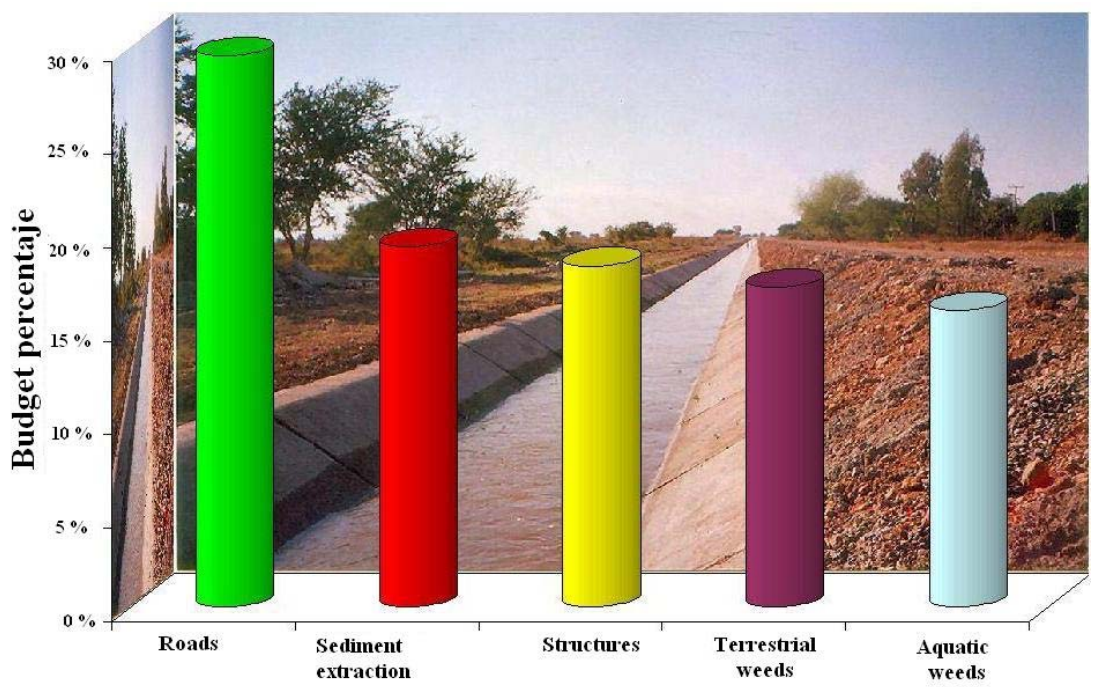

MAINTENANCE WORKS

Figure 4: Distribution of the budget for general maintenance work. 


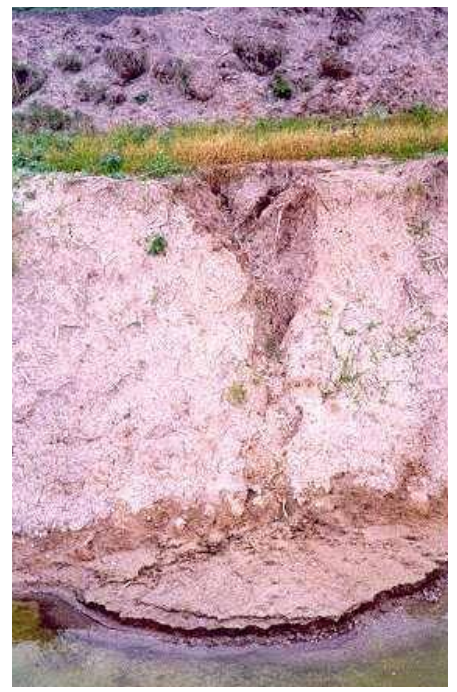

Figure 5: Unprotected slopes cause accumulation of sediments in canals.

The $23 \%$ of the budget in the irrigation districts is used for sediments remove, the distribution of the budget of maintenance works is presented in figure 4 .

To prevent sediments problems in the slopes of canals and drains of $\mathrm{D}$ and $\mathrm{E}$ types, (Table 1) in $90 \%$ of canals and $69.3 \%$ of drains, the National Water Commission in coordination with the Mexican Institute of Water Technology, developed and transferred the technology of using light weight equipments for weed control and allow the growing of grass to protect the slopes, and also facilitate the removal of aquatic weeds in canals and drains. It should be noted that currently there are over 250 light weight equipment of Irrigation Districts.

Table 1: Characteristics and percentages within the national territory of canals and drains.

\begin{tabular}{|c|c|c|c|c|}
\hline \multirow{2}{*}{ Type } & Bottom & Depth of water & Canals & Drains \\
\cline { 4 - 5 } & $(\mathbf{m})$ & $\mathbf{( m )}$ & $\mathbf{( \% )}$ & $\mathbf{( \% )}$ \\
\hline E & Less than 2 & Less than 1.2 & 76.2 & 40.4 \\
D & Between 2 and 4 & Between 1.3 and 1.7 & 13.8 & 28.9 \\
C & Between 4 and 6 & Between 1.8 and 2.4 & 5.4 & 16.9 \\
B & Between 8 and 10 & Between 2.5 and 3.0 & 1.4 & 8.0 \\
A & Between 10 and 20 & More than 3.0 & 3.2 & 5.8 \\
\hline
\end{tabular}

\section{Investment in maintenance}

Under normal conditions, about the $50 \%$ of the Irrigation Districts budget should be invested in maintenance programs, in order to ensure the optimal state of the irrigation systems. 


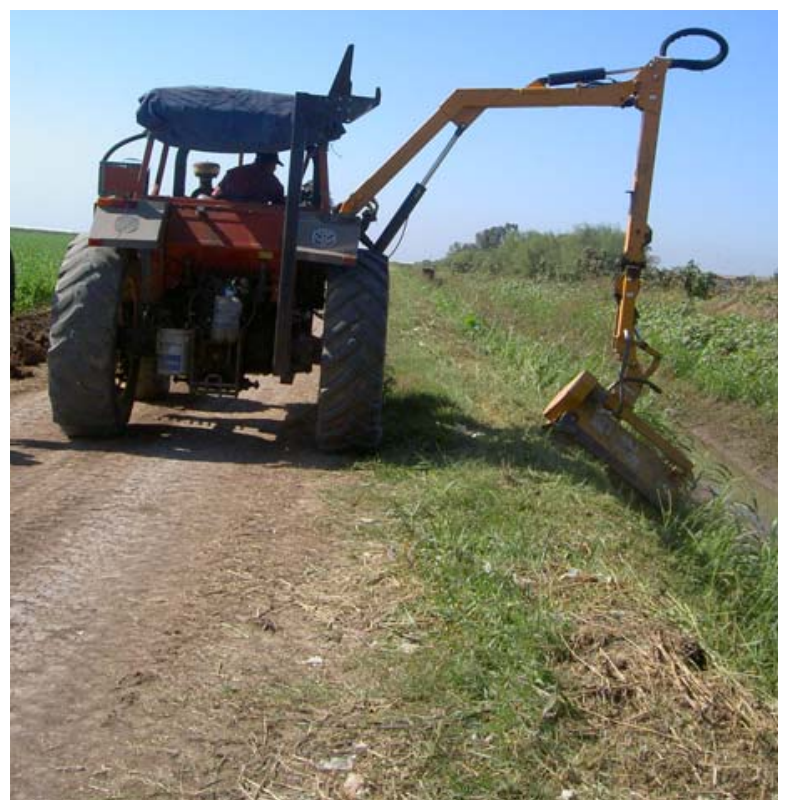

Figure 6: Light weight equipment in an irrigation canal.

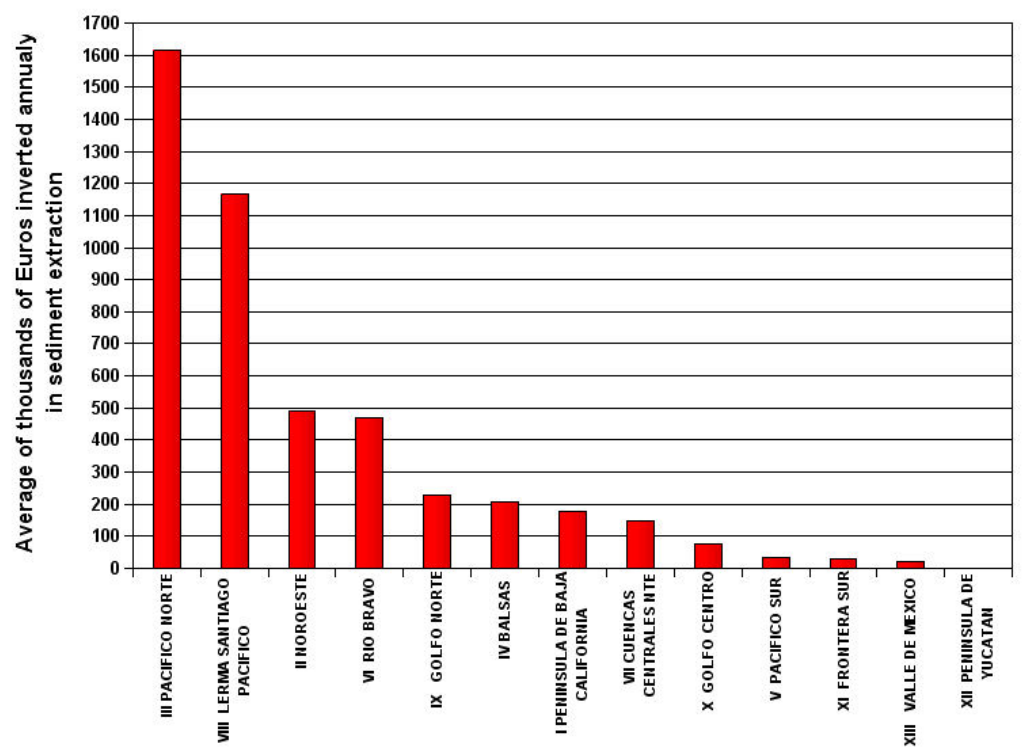

Figure 7: Average budget used in sediments extraction by Agency basin.

The Pacifico Norte Agency Basin invests more than 1'600,000 $€$ in sediments extraction because of the storage dams basins are among the largest in the 
country and are deteriorated. Below is the Agency Basin Lerma Santiago Pacific Basin, which is supplied with water from the Lerma River, one of the largest in the central basin of the country which is heavily damaged.

\section{Conclusions}

The lifetime of most storage dams has decreased significantly due to the sediments accumulation caused by inadequate soil and water conservation works in the catchment basins.

Irrigation Districts in Mexico have upgraded their equipment and machinery to remove sediments and to protect the slopes of canals and drains at lower costs. One fifth of the Irrigation District budget is used to extract sediments. The average maintenance cost is $110 € /$ mile, in the distribution network and 157 $€ /$ mile in the drainage network.

\section{Recommendations}

Enhance the works of soil and water conservation in the impounding basins of the dams of the irrigation districts.

Promote the modernization and technical activities in the irrigation districts, to increase conduction water efficiency and avoid the risk of causing damage to the soil level plots.

\section{References}

[1] Water National Commission, Efficient use of water and electricity Coordination, Small irrigation units organized and unorganized. 1999

[2] Water National Commission. Irrigated areas and volumes of water distributed in the irrigation districts. 2009

[3] Water National Commission. Statistics of irrigation districts. 2009

[4] Water National Commission. Inventories of infrastructure, machinery and equipment of the irrigation districts. 2010 